\title{
Rancang Bangun Interior Architectural Visualization Menggunakan Unreal Engine 4
}

\author{
I Putu Okpin Narwan, Wiwi Widayani, Ika Asti Astuti*, Atik Nurmasani, Irwan Setiawanto, R. \\ Hennry Poerwanto B. \\ Sistem Informasi, Fakultas Ilmu Komputer, Universitas Amikom Yogyakarta \\ J1. Ringroad Utara, Condongcatur, Depok, Sleman, D.I. Yogyakarta Indonesia 55283 \\ *e-mail: asti@amikom.ac.id
}

(received: 26 Juli 2021, revised: 27 Juli 2021, accepted: 10 September 2021)

\begin{abstract}
Abstrak
Architectural visualization mampu memberikan informasi visual mengenai rancangan suatu bangunan tidak hanya pada si pembuat bangunan, melainkan juga untuk masyarakat umum. Hal ini biasanya dipresentasikan menggunakan media gambar dan juga video, adapun metode untuk mengatasi keterbatasan media dalam mempresentasikan rancangan suatu bangunan yaitu dengan mengimplementasikan teknologi architectural walkthrough. Architectural walkthrough adalah animasi simulasi yang memberikan gambaran umum tentang bangunan atau lebih kompleks yang sedang dibangun. Tidak seperti architectural rendering yang menawarkan gambar hanya dari satu sudut pandang saja, architectural walkthrough menampilkan serangkaian gambar yang berbeda dari berbagai sudut pandang yang dapat membantu untuk memperoleh ide yang tepat tentang arsitektur yang digunakan di sekitarnya. Penelitian ini menghasilkan aplikasi architectural visualization interior rumah T.90/15 menggunakan Unreal Engine 4. Pengukuran 4 variabel pada aspek usability memiliki nilai persentase yaitu variabel usefulness $85 \%$, variabel ease of use $80 \%$, variabel ease of learning $84,5 \%$, variabel satisfaction $81,8 \%$. Pengukuran aspek usability secara keseluruhan menghasilkan nilai persentase kelayakan sebesar $82,5 \%$ yang menunjukkan bahwa hasil pengukuran usability aplikasi architectural visualization ini memiliki nilai yang "sangat layak" atau dengan kata lain sistem sangat berguna dalam hal menampilkan visualisasi dari desain interior sebuah rumah.
\end{abstract}

Kata kunci: architectural walkthrough, augmented reality, architectural visualization, unreal engine4.

\begin{abstract}
Architectural visualization is able to provide visual information about the design of a building to the builder and to the general public. This is usually presented using image and video, the method to overcome the limitations of the media in presenting the design of a building is by implementing architectural walkthrough technology. Architectural walkthroughs are simulated animations that provide an overview of the building or complex under construction. Unlike architectural renderings which offer images from only one angle, architectural guides look at different scenes from multiple points of view which can help to get the right idea about the architecture used around them. This study resulted in the application of visualization of the interior architecture of the house T.90/15 using Unreal Engine 4. Measurement of 4 variables in the usability aspect are usability variable $85 \%$, ease of use variable $80 \%$, learning ease variable $84.5 \%$, and satisfaction variable $81,8 \%$. The measurement of the usability aspect as a whole is based on the specified value of $82.5 \%$ which indicates that the measurement results of the usability of this architectural visualization have a "very feasible" value or in other words a very useful system for interior design visualization.
\end{abstract}

Keywords: architectural walkthrough, augmented reality, architectural visualization, unreal engine4.

\section{Pendahuluan}

Muflih Land Developing Future merupakan perusahaan pengembang real estate yang beroperasi di Yogyakarta. Dimana salah satunya, perusahaan menawarkan rumah hunian kosong yang akan dibangun ketika rumah telah resmi dibeli oleh calon pembeli. Sebagai ilustrasi rumah yang akan dibangun pihak perusahaan memberi berupa brosur yang menjelaskan luas persegi dan juga denah rumah yang akan dibangun serta beberapa gambar 3D architectural rendering rumah tersebut kepada 
calon pembeli rumah. Dengan hanya mengandalkan brosur dan juga gambar 3D architectural rendering, baik perusahaan maupun calon pembeli rumah memiliki keterbatasan dalam memvisualkan rumah yang akan dibangun karena gambar 3D architectural rendering hanya mencakup satu sudut pandang saja sehingga adanya sudut pandang ataupun sudut rumah yang tidak dapat divisualisasikan oleh gambar 3D architectural rendering tersebut. Manajer marketing perusahaan tersebut dan calon pembeli rumah tentunya membutuhkan suatu media yang dapat memvisualisasi berbagai sudut rumah sehingga dapat merencanakan interior yang akan digunakan.

Seiring kemajuan teknologi di zaman sekarang ini khususnya dalam bidang architectural visualization, pada dasarnya adalah memberikan informasi visual mengenai rancangan suatu bangunan tidak hanya pada si pembuat bangunan, melainkan juga untuk masyarakat umum. Hal ini biasanya dipresentasikan menggunakan media gambar dan juga video. Dalam mengikuti perkembangan teknologi yang semakin canggih, adapun cara untuk mengatasi keterbatasan media dalam mempresentasikan rancangan suatu bangunan yaitu dengan mengimplementasikan teknologi architectural walkthrough yaitu animasi simulasi yang memberikan gambaran umum tentang bangunan atau lebih kompleks yang sedang dibangun [1]. Tidak seperti architectural rendering yang menawarkan gambar hanya dari satu sudut pandang saja, architectural walkthrough pada dasarnya adalah serangkaian gambar yang berbeda dari berbagai sudut pandang yang dapat membantu untuk memperoleh ide yang tepat tentang arsitektur yang digunakan di sekitarnya [2].

Aplikasi Walkthrough memungkinkan pengguna untuk merasa seolah-olah mereka berada disana, berjalan di sekitar lanskap, pencahayaan yang realistis, bayangan, dan efek lainnya. Kemampuan Game Engine untuk mengembangkan aplikasi Real-Time Walkthrough dapat menguntungkan industri Architecture, Engineering and Construction atau disingkat menjadi AEC, misalnya pemilik proyek konstruksi dapat dengan bebas menetapkan fasilitas virtual lebih awal sehingga dapat menetapkan hasil akhir dengan lebih baik lagi, dari pada hanya melihat representasi dalam bentuk gambar statis [6]. Real-Time Rendering adalah pembuatan gambar dari sebuah adegan atau model. Hal ini dapat dikerjakan hanya dalam mili detik, atau bahkan berjam - jam. Ketika sebuah program dapat membuat adegan tertentu dalam waktu kurang dari 33 mili detik (memperbarui gambar lebih dari 30 kali per detik) di sebut "Real Time". Sebagian besar video game membuat grafik secara real time sebaliknya sebagian besar film tidak dibuat secara real time [7].

Game Engine adalah sistem software yang didesain untuk pembuatan dan pengembangan video games. Fungsi utama dari game engine adalah melakukan graphic processing dalam hal ini biasa disebut dengan rendering (cara grafik komputer membuat gambaran dari informasi seperti bentuk, tekstur, pencahayaan, dan bayangan), collision detection (metode perhitungan fisika ketika terjadi benturan antara dua obyek), scripting, animasi, pengaturan suara dan sebagainya. Dengan menggunakan game engine, programmer tidak harus menulis kode pemrograman dari awal [8]. Game engine mempunyai fungsi berupa rendering untuk model 2D atau 3D grafik, deteksi tepi, suara, skrip, animasi dan kecerdasan buatan. Game engine dapat disebut sebagai "Game Middleware". Game middleware merupakan software yang sudah memiliki elemen-elemen yang dapat digunakan oleh pembuat permainan, fitur yang diberikan oleh permainan middleware dapat memberikan manfaat dalam hal pengembangan permainan seperti pembuatan suara, animasi, karakter dan kecerdasan buatan [9].

3D Game Engine tidak hanya digunakan untuk membuat game, tetapi juga digunakan untuk menggambarkan sebuah lingkungan virtual dalam keadaan real time dan realistis. Salah satu perguruan tinggi mengajarkan game engine untuk desain arsitektur, yaitu University of 12 Southern Mississippi. Perguruan tinggi tersebut beranggapan bahwa seseorang yang menggunakan game engine bisa membangun bentuk desain arsitektur bangunan lebih cepat dibandingkan dengan menggunakan alat tiga dimensi biasa [3].

\section{Tinjauan Literatur}

Unity 3D Engine pernah diterapkan dalam Peta Interaktif Tiga Dimensi Gedung Rektorat Institut Teknologi Sepuluh Nopember peta 3D ini dapat memberikan informasi dan menunjukan keadaan dari area dan gedung Rektorat secara lengkap dan mendetail, sehingga pengguna dapat mengetahui keadaan nyata dari map yang digambarkan lebih mudah.dilakukan uji fungsional dan non fungsional untuk mengukur performa aplikasi di beberapa spesifikasi komputer berbeda [3]. Penggunaan 
Software Game Engine yang bertindak sebagai proses dan solusi desain dinamis karena kebebasan dan pilihan tanpa batas yang dapat ditawarkan oleh Software tersebut ke bidang desain interior, juga dapat memberikan peluang untuk perbandingan dengan desain lainnya.Pengujian dilakukan dengan mendesain empat ruangan sebuah apartemen dengan total luas $169 \mathrm{~m} 2$ yang merupakan proyek dari Residential Building Saffron Garden yang berada di pusat kota Kosice, Slovakia. Hasil pengujian memungkinkan pembuatan anggaran terperinci untuk desain interior yang dapat membantu pelanggan memperoleh gambaran umum dari total biaya yang terkait dengan pembelian apartemen serta furniturnya. Harga apartemen yang disebutkan oleh pengembang adalah 315.000 EUR termasuk PPN, sedangkan harga furniture yang terhitung oleh aplikasi adalah 30.740 EUR termasuk PPN yang merupakan 9,76\% dari harga pembelian [4].

Penyelidikan desain interaksi yang efektif untuk mengembangkan aplikasi web virtual tour kampus yang menawarkan pengalaman yang berbeda di lingkungan alami melalui penerapan teknologi non-imersif. Penelitian ini menggunakan metode Low-Fidelity Interface Design, Brainstorming dan Virtual Tour Prototype Development. Hasil penelitian ini menunjukan fitur tampilan informasi yang dapat diimplementasikan dalam desain virtual tour kampus, sehingga mencegah masalah beban kognitif dan navigasi yang sering terjadi di sistem virtual tour yang ada. Beban kognitif mengacu pada total memori yang digunakan, setiap desain antarmuka harus dirancang mempertimbangkan persyaratan kemampuan kognitif, dan keterbatasan pengguna. Tampilan grafis yang menyeluruh, sederhana, dan menarik serta posisi tautan menu dan tombol yang jelas akan memudahkan pengguna menggunakan aplikasi [5]. Berbeda dengan 3 penelitian sebelum, pada penelitian ini akan memanfaatkan Unreal Engine 4 untuk membuat aplikasi architectural visualization. Aplikasi dibuat dalam bentuk aplikasi walkthrough dimana user dapat dengan bebas menelusuri rumah hunian yang akan di bangun. User juga dapat berinteraksi langsung dengan objekobjek yang ada dalam aplikasi ini seperti mengganti material yang digunakan serta menghidupkan dan mematikan TV pada rumah tersebut.

Unreal Engine 4 diperlihatkan kepada publik selama GDC (Game Dev Conference) 2012, dengan demo yang mengesankan yang dianggap sebagai sinematik sampai Epic Games menunjukkan itu adalah cuplikan gameplay yang sebenarnya. Di tahun 2014 Unreal Engine 4 dirilis dengan biaya berlangganan $+5 \%$ dari pendapatan kotor yang dihasilkan dari penggunaan komersial produk yang dibuat menggunakan UE4. Maret 2015, Unreal Engine menjadi tersedia untuk semua orang secara gratis bersama dengan semua pembaruan di masa depan, dengan satu-satunya biaya dari jadwal royalti selektif. Unreal Engine 4 telah menjadi sumber yang sangat kuat baik untuk pengembangan indie dan profesional, menjadi pilihan yang tepat untuk memulai tetapi juga mesin yang kuat untuk game AAA [10][11]. Unreal Engine adalah sebuah Game Engine yang dikembangkan oleh Epic Games, Unreal Engine hadir dgn sistem pengkodean menggunakan bahasa pemrograman $\mathrm{C}++$ [8]. Unreal Engine juga yang bertindak dan mengatur pada setiap objek yang dibuat agar berjalan dengan teratur, dan Unreal Engine juga dapat memberikan warna pada tekstur objek, kontras apda lingkungan dan pada karakter yang digunakan maupun musuh yang berada didalam game tersebut [12]. Unreal Engine adalah sebuah Game Engine yang digunakan untuk membuat game. Ada sejumlah alat profesional yang kami gunakan untuk mewujudkan tujuan kami, yang paling menonjol adalah unreal engine 4 yang bertindak sebagai kompiler yang mengatur masing-masing objek individu yang dibuat secara berurutan dan dalam urutan yang tepat hal ini juga digunakan untuk memberikan warna, tekstur dan kontras dari lingkungan dan karakter. Sementara aset permainan dapat dikembangkan di perangkat lunak lain, engine 4 tidak nyata digunakan untuk memodifikasi aset ini hanya agar terlihat lebih realistis dan indah [13]. Unreal Engine adalah software terintegrasi pengembang game untuk merancang dan membangun game, simulasi, dan visualisasi [14][15].

\section{Metode Penelitian}

Metode penelitian yang digunakan oleh penulis dalam penelitian ini adalah metode pengembangan multimedia, yaitu mulai dari merancang konsep, merancang isi, menulis naskah, memproduksi system, dan melakukan pengujian system seperti digambarkan pada Gambar 1. 


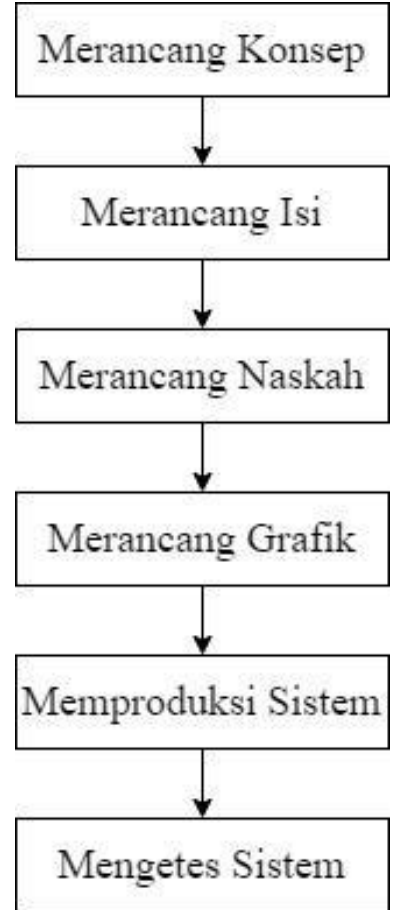

\section{Gambar 1. Siklus Pengembangan Sistem Multimedia}

Pengembangan sistem multimedia yang dilakukan pada penelitian ini terdapat 6 tahapan yaitu Merancang Konsep, Isi, Naskah, Grafik, Memproduksi Sistem, dan Mengetes Sistem. Pada tahapan pertama dilakukan pembuatan konsep sesuai dengan kebutuhan aplikasi. Merancang Isi yaitu mengimplementasikan konsep dalam bentuk struktur navigasi. Pada tahapan merancang naskah dilakukan perumusan detail deskripsi untuk setiap menu pada aplikasi sesuai konsep dan isi. Selanjutnya yaitu membuat rancangan grafik untuk setiap menu yang ada pada aplikasi. Pada tahapan memproduksi Sistem dilakukan pembuatan asset serta program yang digunakan dalam aplikasi architectural visualization, terdiri dari 8 aktivitas yaitu pembuatan 3D model, pembuatan texture, pembuatan scene, penerapan lightning, pembuatan material, implementasi antarmuka aplikasi, pembuatan script, dan finishing. Terakhir, dilakukan pengujian pada aplikasi dengan metode pengujian white box dan black box serta pengujian usability.

\section{Hasil dan Pembahasan}

\subsection{Merancang Konsep}

Urutan pertama dari aplikasi ini adalah intro loading yang berupa animasi logo Unreal Engine dan perusahaan Muflih Land Developing Future. Kemudian menuju halaman utama yaitu menu utama pada aplikasi ini yang didalamnya berisi tombol-tombol yang menuju halaman sesuai dengan yang dipilih oleh user. Di halaman selanjutnya akan ada tombol kembali, yaitu tombol yang akan mengembalikan user ke halaman utama dari aplikasi ini. Terdapat menu walkthrough, profil dan bantuan pada menu utama yang akan mengarahkan user ke menu selanjutnya sesuai dengan tombol yang ditekan. Dan terdapat tombol keluar jika user ingin menghentikan aplikasi.

\subsection{Merancang Isi}

Pada tahap kedua dibuat struktur navigasi agar alur sistem yang akan dibuat lebih jelas. Aplikasi yang akan dibuat akan diisi dengan beberapa elemen antara lain: 3D model, teks, gambar, suara, animasi dan video yang keseluruhannya akan ditempatkan kedalam beberapa bagian menu. Struktur navigasi merupakan bagan alur dari suatu aplikasi. Dalam aplikasi architectural visualization ini dibuat struktur navigasi jenis komposit/campuran agar isi aplikasi terlihat lebih jelas alurnya. Gambar 2 merupakan struktur navigasi dalam aplikasi architectural visualization yang akan dibangun. 


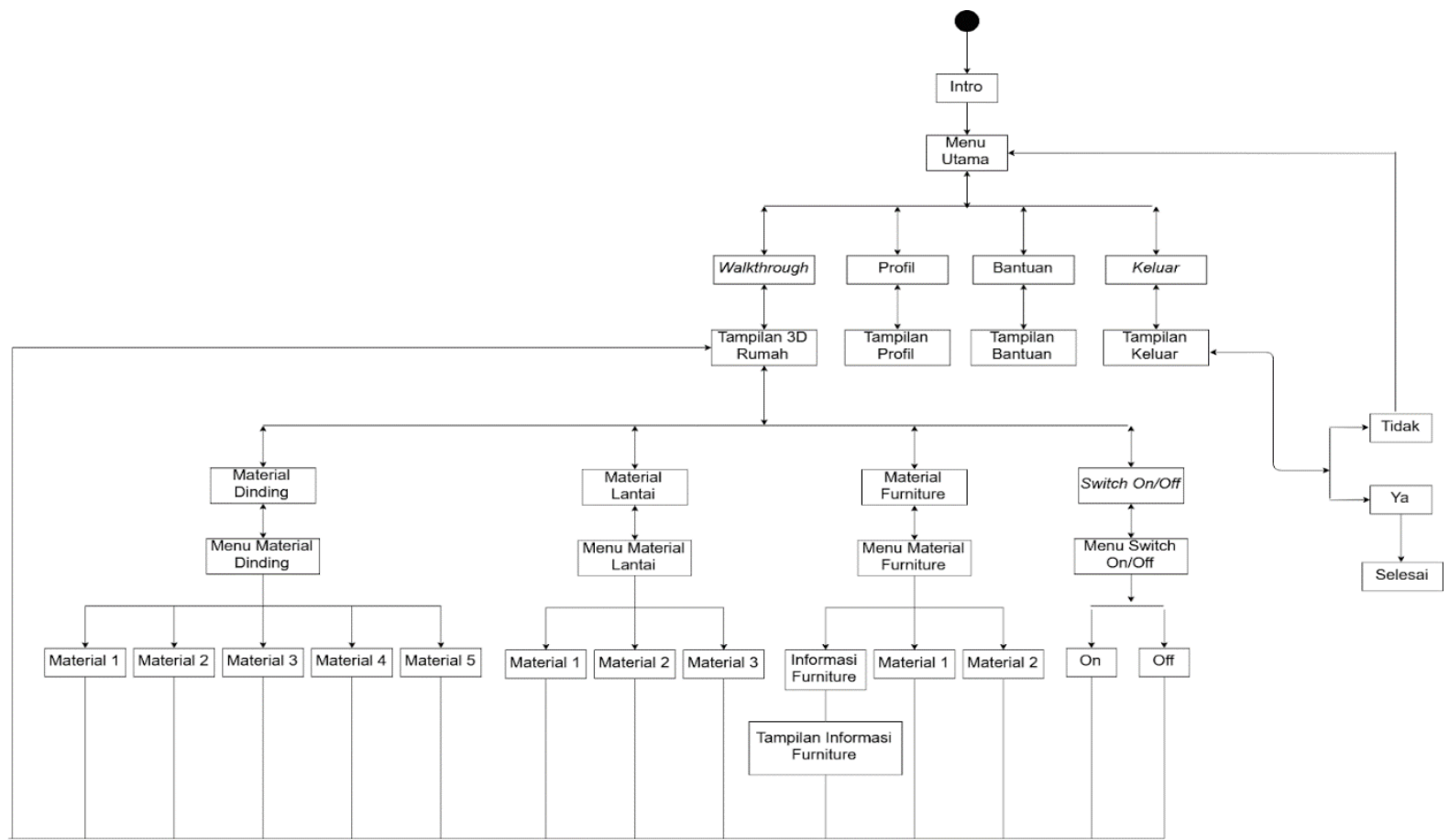

\section{Gambar 2. Struktur Navigasi Aplikasi}

Gambar 2 merupakan rancangan struktur navigasi yang digunakan pada aplikasi. Terdapat 4 menu yaitu Walkthrough, Profil, Bantuan dan Keluar. Pada Menu Walkthrough terdapat sub menu Tampilan Rumah 3D dimana didalam menu ini terdapat sub menu untuk informasi lainnya yaitu Material Dinding, lantai, furniture dan switch on/off. Keterangan lebih lanjut pada menu ini dijelaskan pada Tabel 1.

\subsection{Merancang Naskah}

Tahap ketiga adalah merancang naskah. Aplikasi ini dirancang dalam bentuk menu-menu pilihan sederhana dengan maksud agar mudah dioprasikan. Selain menu dan teks juga disediakan simbolsimbol pada sebuah tombol. Rancangan naskah aplikasi ini dapat dilihat pada Tabel 1.

Tabel 1. Rancangan Naskah

\begin{tabular}{|c|c|c|}
\hline No. & Menu & Deskripsi \\
\hline 1 & Intro & Animasi Logo Perusahaan \\
\hline 2 & Menu Utama & $\begin{array}{l}\text { Menu Utama berisi: } \\
\text { 1.Tombol Profil } \\
\text { 2.Tombol Bantuan } \\
\text { 3.Tombol Walkthrough } \\
\text { 4.Tombol Keluar }\end{array}$ \\
\hline 3 & Menu Profil & $\begin{array}{l}\text { Dalam Menu profil berisi gambar dan teks dalam halaman profil. } \\
\text { Menjelaskan secara singkat tentang rumah hunian yang akan } \\
\text { dibangun mulai dari denah dan luas perseginya. }\end{array}$ \\
\hline 4 & $\begin{array}{l}\text { Menu } \\
\text { Bantuan }\end{array}$ & Dalam menu bantuan berisi bantuan cara menggunakan aplikasi. \\
\hline 5 & $\begin{array}{l}\text { Menu } \\
\text { Walkthrough }\end{array}$ & $\begin{array}{l}\text { Dalam menu Walkthrough akan terdapat } 4 \text { jenis tombol yang dapat } \\
\text { dijumpai oleh user ketika user berada dalam suatu ruangan. Tombol } \\
\text { yang dimaksud yaitu Material Dinding, Material Lantai, Material } \\
\text { Furniture dan switch on/off dimana masing-masing tombol memiliki } \\
\text { fungsinya masing-masing. }\end{array}$ \\
\hline $5 \mathrm{a}$ & Menu & Menu material dinding terdapat 5 tombol pilihan material yang \\
\hline
\end{tabular}




\begin{tabular}{c|l|l}
\hline No. & \multicolumn{1}{|c}{ Menu } & \multicolumn{1}{c}{ Deskripsi } \\
\hline & $\begin{array}{l}\text { Material } \\
\text { Dinding }\end{array}$ & digunakan oleh user untuk mengganti warna dinding rumah tersebut. \\
\hline $5 \mathrm{~b}$ & $\begin{array}{l}\text { Menu } \\
\text { Material } \\
\text { Lantai }\end{array}$ & $\begin{array}{l}\text { Menu material lantai terdapat 3 tombol pilihan material yang } \\
\text { digunakan oleh user untuk mengganti warna atau material lantai } \\
\text { rumah tersebut. }\end{array}$ \\
\hline $5 \mathrm{c}$ & $\begin{array}{l}\text { Menu } \\
\text { Material } \\
\text { Furniture }\end{array}$ & $\begin{array}{l}\text { Menu material furniture terdapat tombol informasi furniture dan } \\
\text { memiliki jumlah tombol yang digunakan untuk mengganti material } \\
\text { furniture yang berbeda-beda. }\end{array}$ \\
\hline $5 \mathrm{c} .1$ & $\begin{array}{l}\text { Menu } \\
\text { Informasi } \\
\text { Furniture }\end{array}$ & $\begin{array}{l}\text { Menu informasi furniture terdapat gambar dan juga informasi singkat } \\
\text { mengenai furniture yang digunakan. }\end{array}$ \\
\hline $5 \mathrm{~d}$ & $\begin{array}{l}\text { Menu switch } \\
\text { on/off }\end{array}$ & $\begin{array}{l}\text { Menu switch on/off terdapat 2 pilihan tombol yaitu tombol On dan } \\
\text { Off. Dimana tombol ini digunakan untuk menghidupkan atau } \\
\text { mematikan perangkat elektronik yang ada dalam rumah. }\end{array}$ \\
\hline 6 & Menu Keluar & $\begin{array}{l}\text { Menu tombol keluar terdapat 2 pilihan tombol yaitu tombol Ya untuk } \\
\text { keluar dari aplikasi dan Tidak untuk tetap menjalankan aplikasi } \\
\text { kembali. }\end{array}$ \\
\hline
\end{tabular}

\subsection{Merancang Grafis}

Merancang grafik meliputi merancang tombol, posisi background, posisi animasi dan lain-lain. Grafik yang dirancang disesuaikan dengan menu-menu yang ada pada Tabel 1. Salah satu contoh yang dirancang dalam tahapan ini terdapat pada Gambar 3.

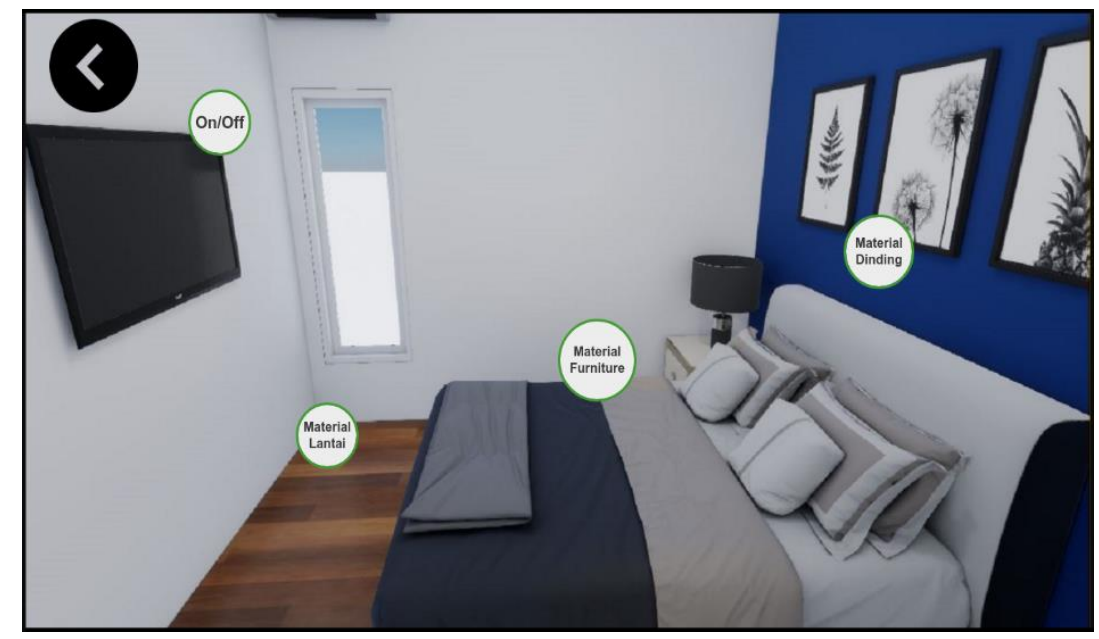

Gambar 3. Merancang Grafik Menu Walkthrough

Gambar 3 merupakan contoh tampilan di salah satu desain interior pada Menu Walkthrough. Di dalam menu walkthrough user akan mengendalikan satu karakter first person perspective (FPP) dan di dalam menu walkthrough semua tombol akan di hide (disembunyikan). Tombol akan muncul ketika user berada didekat suatu objek atau furniture tertentu. Dalam menu walkthrough terdapat 4 jenis tombol yang berbeda beda diantaranya tombol material dinding, lantai, furniture dan tombol switch on/off.

\subsection{Memproduksi Sistem}

\subsubsection{Pembuatan 3D Model}

Aktivitas pertama, pembuatan 3D model yang ada dalam aplikasi architectural visualization ini dibuat berdasarkan real objek yang bereferensi dari berbagai sumber. Untuk referensi 3D model rumah sendiri dibuat berdasarkan Lembar Kerja Rumah T.90/152. Denah Lembar Kerja rumah dapat dilihat pada Gambar 4. 


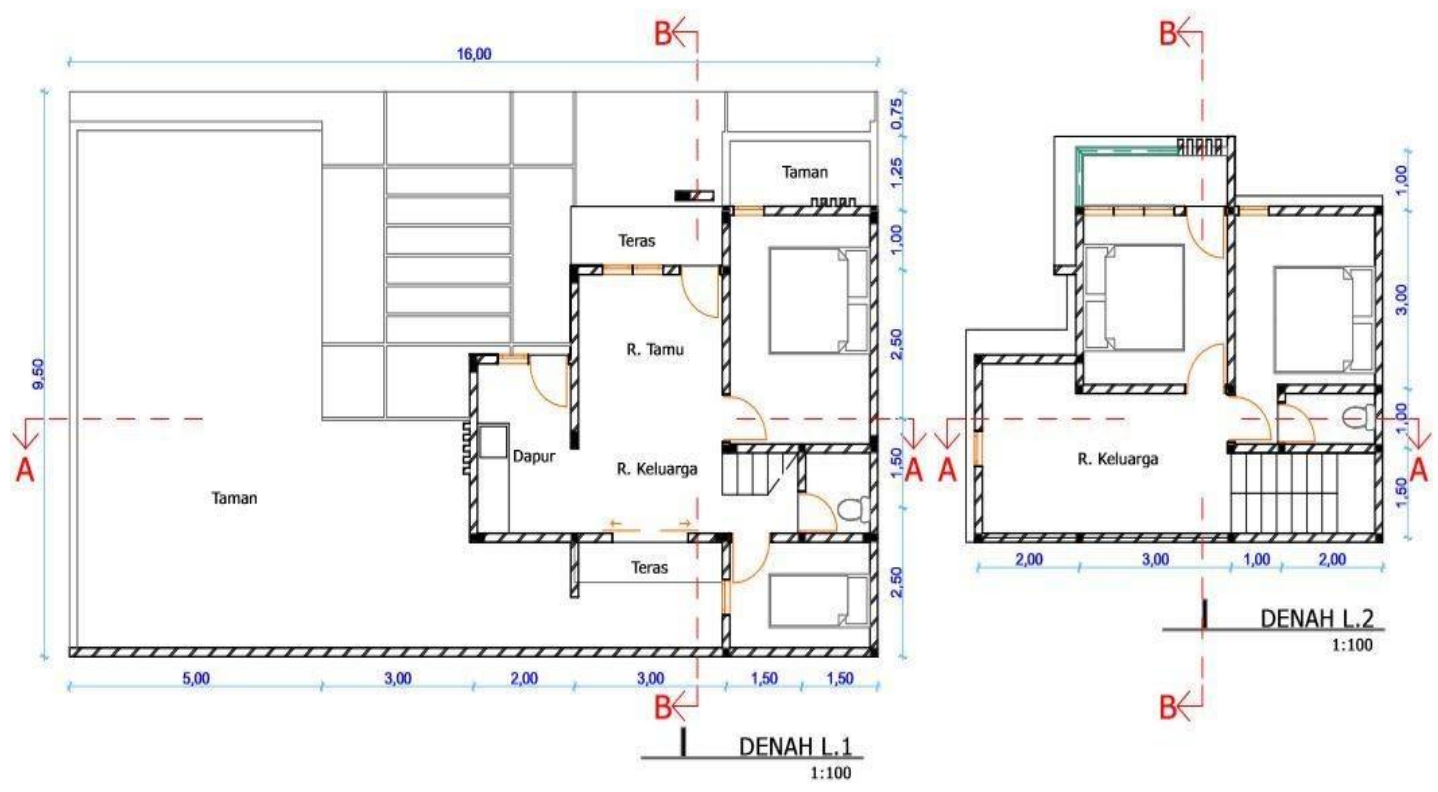

Gambar 4. Denar Lembar Kerja Rumah T.90/152

Pada Gambar 4 merupakan informasi denah ruangan sebuah rumah yang digunakan dalam aplikasi. Tahap pembuatan 3D model sendiri dibagi menjadi 2 berdasarkan teknik pembuatannya, diantaranya 3D model rumah dan furniture dibuat menggunakan Blender serta pembuatan 3D model fabric dibuat menggunakan Marvelous Designer. 3D model yang ada dalam aplikasi architectural visualization ini dibuat bedasarkan real objek yang bereferensi dari berbagai sumber. Untuk referensi 3D model rumah sendiri dibuat berdasarkan Lembar Kerja Rumah T.90/152 sedangkan untuk 3D model furniture bereferensi dari berbagai website properti yang menyantumkan spesifikasi singkat tentang furniture tersebut, seperti www.dekoruma.com, www.houzz.com, www.polytron.co.id, dan lain-lain.

\subsubsection{Pembuatan Texture}

Aktivitas kedua, pembuatan texture berdasarkan 3D model yang telah dibuat sebelumnya dan di export ke file .fbx kemudian akan di lakukan 3D painting menggunakan Substance Painter seperti yang terlihat pada Gambar 5. Kemudian lakukan export texture dengan file .PNG.
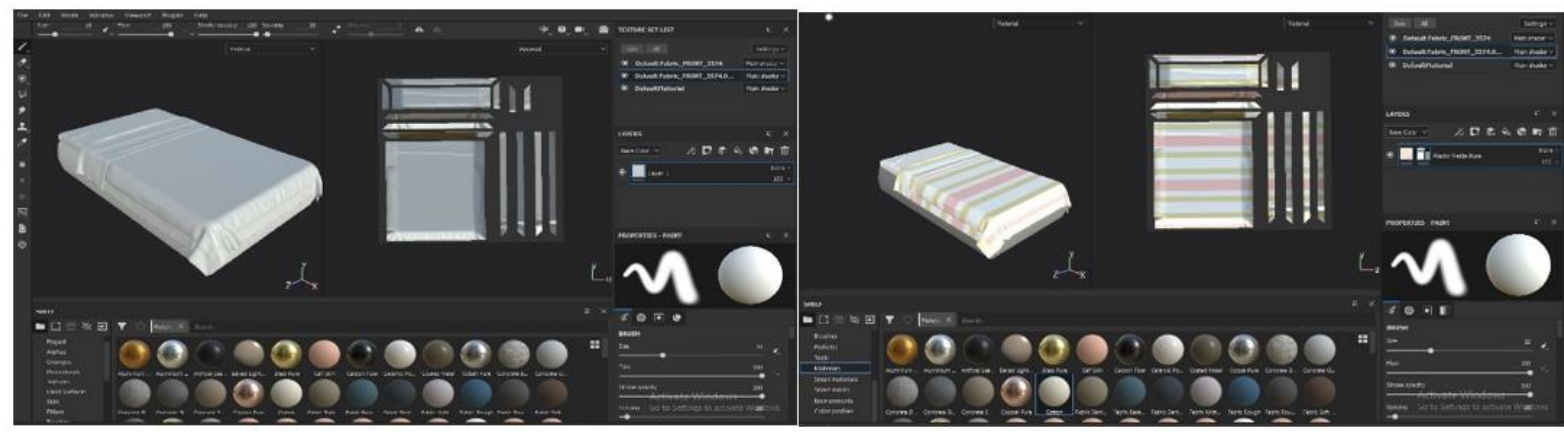

Gambar 5. Hasil sebelum (kanan) dan sesudah (kiri) 3D Painting

3D model yang telah dibuat sebelumnya dan di export ke file .fbx kemudian akan di lakukan 3D painting menggunakan Substance Painter. Teknik 3D painting dilakukan dengan memilih material yang akan digunakan dan menggunakan black mask sebagai pemetaan material yang di pilih kedalam UV map 3D model tersebut. Kemudian gunakan alpha brush untuk menambah gambar (logo) pada 3D model yang diinginkan. Proses 3D painting ini dilakukan hampir di keseluruh objek yang akan di 
gunakan, sedangkan objek yang tidak dilakukan 3D painting akan dibuatkan material menggunakan material node dalam aplikasi Unreal Engine 4.

\subsubsection{Pembuatan Scene}

Aktivitas ketiga, pembuatan scene dimulai dari mengimport semua asset yang telah dibuat sebelumnya. Kemudian dilakukan pembuatan material putih pada Unreal Engine 4. Material ini digunakan saat melakukan build lightning. Salah satu contoh yang dirancang dalam tahapan ini terdapat pada Gambar 6.

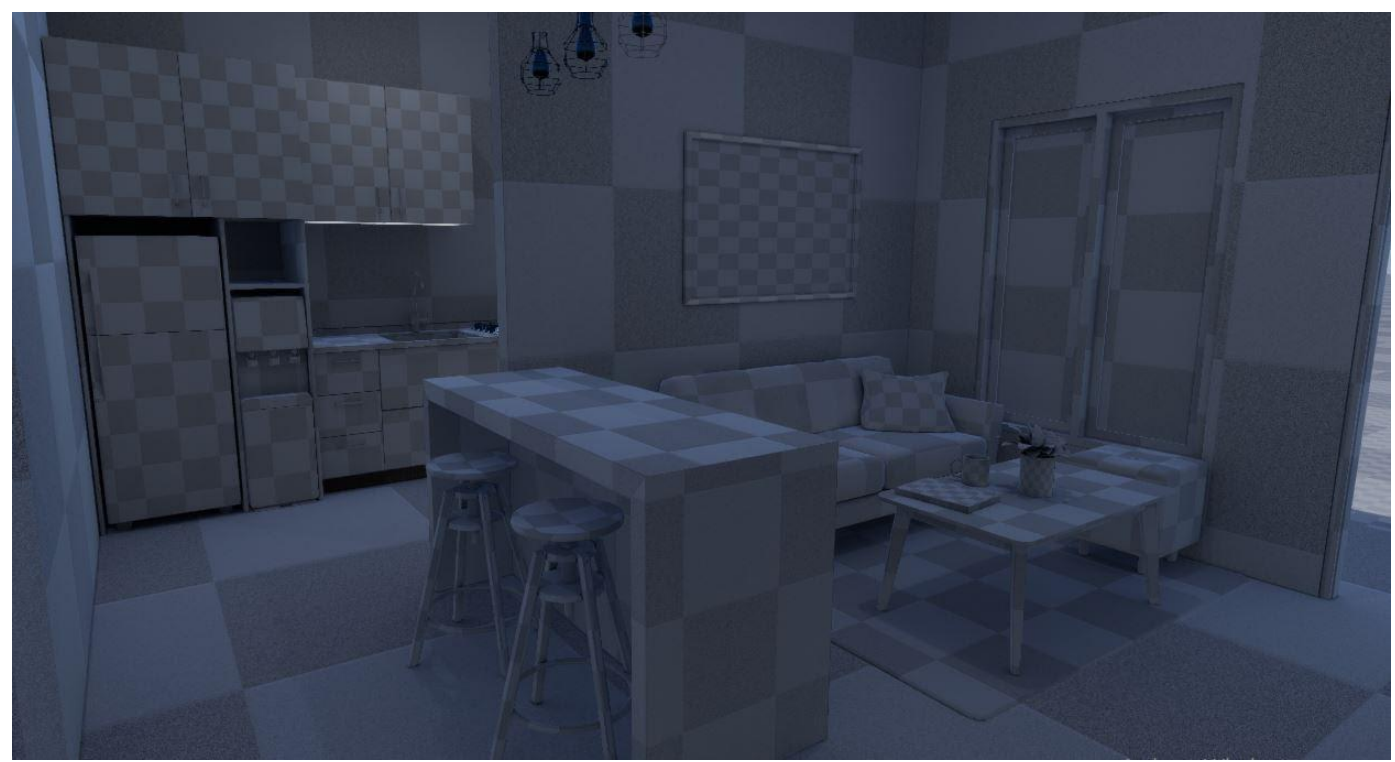

Gambar 6. Scene Ruang Tamu

Pemilihan material putih saat melakukan build lightning karena warna putih dapat memantulkan cahaya dengan baik sedangkan material warna lain seperti biru, merah dan hijau memantulkan cahaya dengan buruk dan dapat mengubah warna cahaya saat dipantulkan sehingga shadow yang di bake berubah menjadi warna tersebut. Pembuatan material putih hanya menggunakan satu node Constant3vektor yang diubah menjadi warna putih sebagai Base Color.

\subsubsection{Penerapan Lightning}

Aktivitas keempat, penerapan lightning dengan tipe baked lightning dan menggunakan beberapa jenis lightning yang diatur mobility secara stationary. Jenis lightning yang digunakan yaitu:

1. 1 buah IndirectLightning (dikonfigurasi secara default),

2. 1 buah SkyLightning (konfigurasi Lightning Intesity 2.5), dan

3. 11 buah SpotLightning (konfigurasi Intensity 1.5 candelas, Inner Cone Angle 45 dan outer Cone Angle 90).

Sebelum dilakukannya bake lightning ada beberapa setup yang dilakukan antara lain:

1. Menggunakan lightmassPortal di setiap jendala dan pintu, dimana portal ini digunakan sebagai arah masuknya cahaya dari luar ke dalam ruangan.

2. Deactivate Auto exposure.

3. Deactivate screen space ambient occlusion (SSAO) dan screen space reflections (SSR).

4. Vignetting $=$ off.

5. Bloom $=$ off.

6. Menggunakan LightmassImportanceVolume dan Atmospheric Fog

Salah satu contoh hasil dari tahapan ini terdapat pada Gambar 7. 


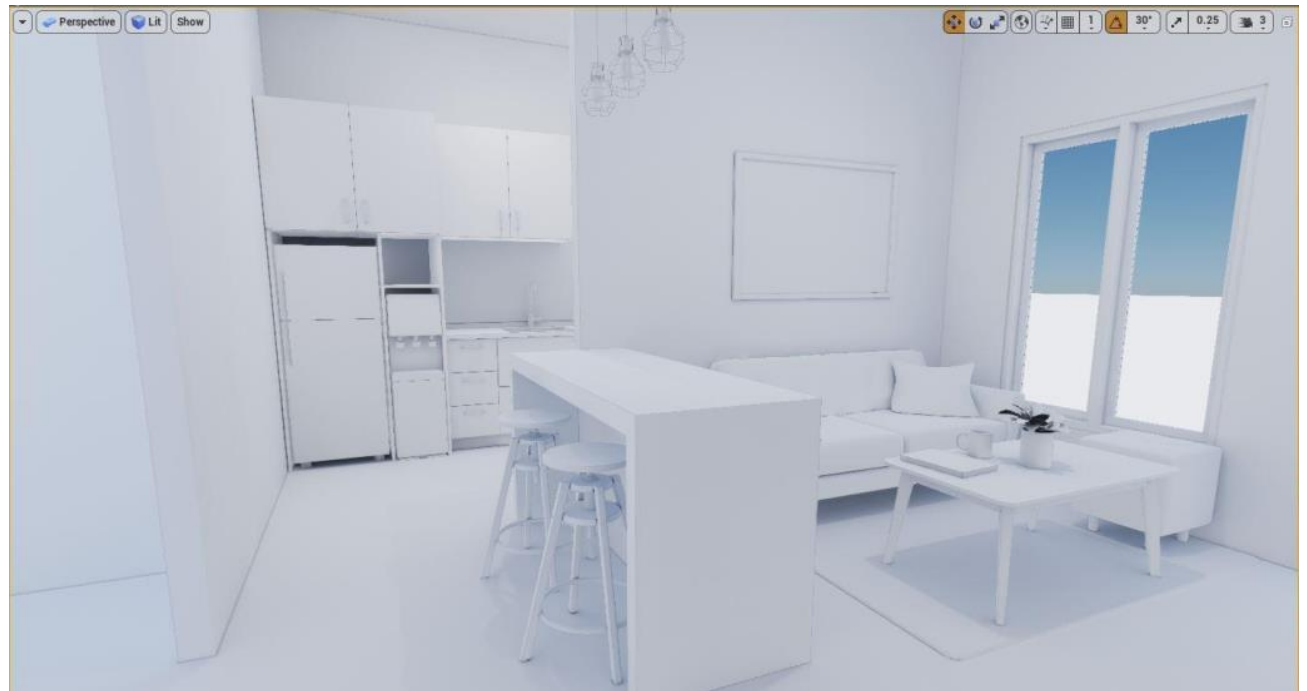

\section{Gambar 7. Scene yang telah diberi lighting}

Konfigurasi lightmass setting pada menu worldsetting yang digunakan adalah Static Lightning Level Scale $=0.1$, Num Inderect Lightning Bounces $=15$, Num Sky Lightning Bounces $=15$, Inderect Lightning Quality = 10, Diactivate Compress Lightmaps.

\subsubsection{Pembuatan Material}

Aktivitas kelima, pembuatan material dengan menggunakan texture sample yang telah dibuat sebelumnya pada aplikasi Substance Painter. Adapun jenis-jenis texture sample yang digunakan yaitu Base color map, Normal map dan Occlusion Roughness Metallic map. Salah satu contoh yang dirancang dalam tahapan ini terdapat pada Gambar 8.

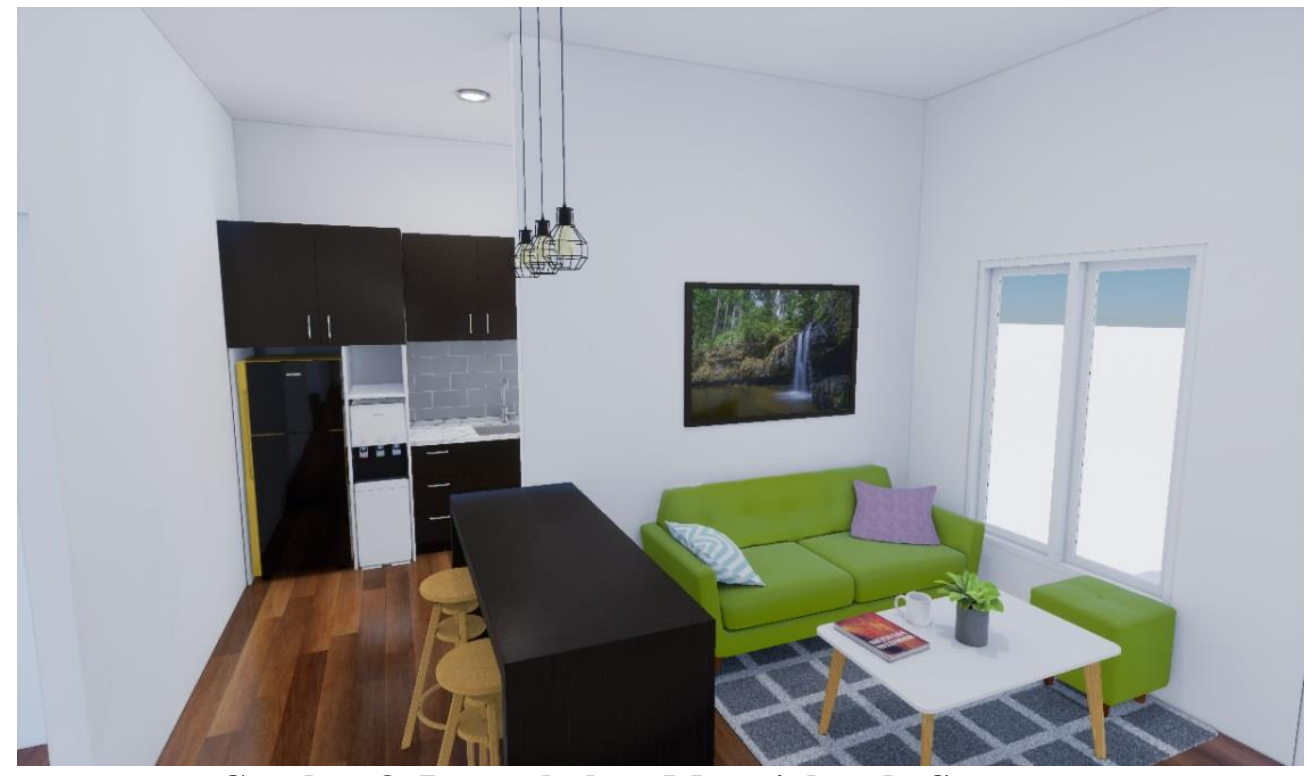

Gambar 8. Penambahan Material pada Scene

Setelah pembuatan material objek selesai maka material objek pada viewport dapat di rubah dengan cara drag and drop material yang sudah dibuat pada objek di viewport. Contoh material yang digunakan yaitu warna pada tembok, tekstur pada furniture sehingga terlihat seperti kayu, kain pada sofa dan bantal serta teksture lantai. 


\subsubsection{Implementasi antarmuka aplikasi}

Aktivitas keenam, implementasi seluruh antarmuka pada aplikasi. Implementasi dibuat berdasarkan rancangan grafik pada Tabel 1, yaitu 11 antarmuka. Beberapa contoh implementasi tampilan antarmuka aplikasi terdapat pada Gambar 9.
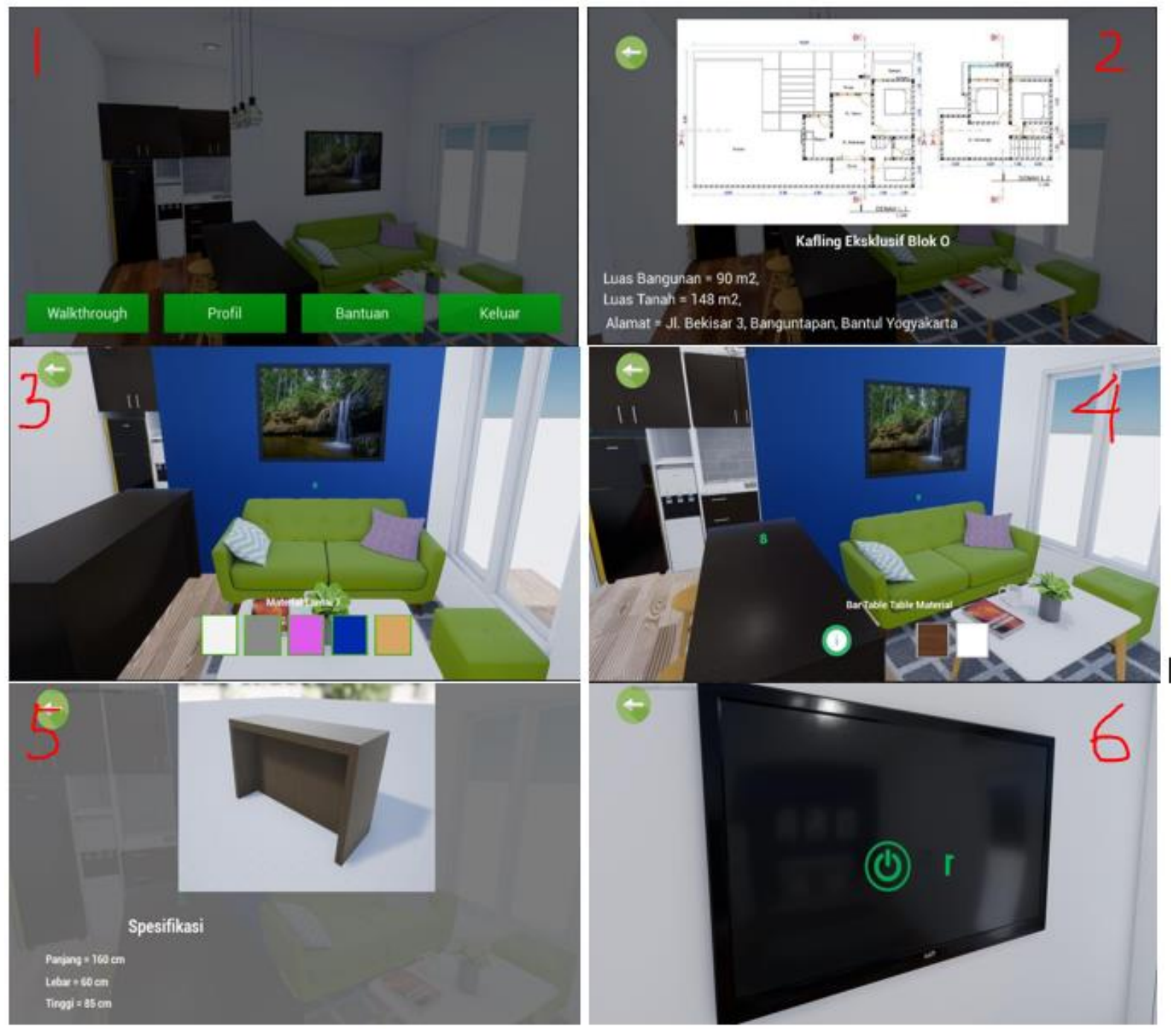

\section{Gambar 9. Implementasi antarmuka Menu Utama (1), Menu Profil (2), Menu Material Dinding (3), Menu Material Furniture (4), Menu Informasi Furniture (5), Menu Switch on/off (6)}

Menu utama adalah menu yang digunakan untuk menavigasi ke halaman menu selanjutnya. Pada Menu material, user dapat memilih menu material lain seperti warna/ tekstur yang digunakan untuk mengganti material pada dinding, lantai ataupun furniture yang ada dalam rumah. User juga dapat melihat informasi spesifikasi furniture yang ada serta user dapat melakukan uji coba on/off pada beberapa perangkat seperti TV atau saklar lampu.

\subsubsection{Pembuatan Script}

Aktivitas ketujuh, pembuatan script menggunakan Unreal Blueprint dilakukan untuk pemberian logika kepada tombol-tombol maupun objek yang ada pada aplikasi architectural visualization ini adapun macam - macam blueprint yang dibuat adalah Blueprint Player (blueprint yang digunakan untuk menggerakan player di dalam aplikasi), Blueprint Changing Materials (blueprint yang digunakan untuk mengganti material pada mesh atau objek), Blueprint switch On/Off (blueprint yang digunakan untuk menghidupkan dan mematikan TV dan memutar Video yang ada di dalamnya). 


\subsubsection{Finishing}

Aktivitas kedelapan, finishing atau tahap akhir dalam pembuatan aplikasi architectural visualization. Finishing dilakukan dengan Menambahkan SphereReflection pada viewport. SphereReflection ini digunakan untuk memberi efek refleksi (pantulan) pada objek-objek yang menggunakan material metallic (metal), melakukan Build Lightning dengan kualitas production dan mengeksport aplikasi kedalam file .apk.

\subsection{Mengetes Sistem}

Tahap Keenam, pengujian aplikasi dengan pengujian white box dan blackbox serta pengujian usability. Hasil pengujian white box dan black box dapat dijabarkan pada Tabel 2 .

\section{Tabel 2. Pengujian White Box dan Black Box}

\begin{tabular}{|c|c|c|c|}
\hline No. & Kelas Uji & Butir Uji & $\begin{array}{c}\text { Jenis } \\
\text { Pengujian }\end{array}$ \\
\hline 1. & Menu utama & $\begin{array}{l}\text { - Tampilkan menu walkthrough } \\
\text { - Tampilkan menu profil } \\
\text { - Tampilkan menu bantuan } \\
\text { - Tampilkan menu keluar }\end{array}$ & Black box \\
\hline 2. & Tombol kontroller & $\begin{array}{ll}\text { - } & \text { Bergerak kedepan } \\
\text { - } & \text { Bergerak kebelakang } \\
\text { - } & \text { Bergerak ke kiri } \\
\text { - } & \text { Memutar kamera menggunakan mouse }\end{array}$ & Black box \\
\hline 3. & $\begin{array}{l}\text { Menu informasi } \\
\text { furniture }\end{array}$ & $\begin{array}{l}\text { - } \quad \text { Menampilkan menu informasi furniture } \\
\text { - Kembali ke menu walkthrough }\end{array}$ & Black box \\
\hline 4. & Menu keluar & $\begin{array}{ll}\text { - } & \text { Menampilkan menu keluar } \\
\text { - } & \text { Keluar aplikasi } \\
\text { - } & \text { Kembali ke menu utama }\end{array}$ & Black box \\
\hline 5. & Collision detection & $\begin{array}{l}\text { - } \begin{array}{l}\text { Collision detection pada tombol material } \\
\text { dinding }\end{array} \\
\text { - } \\
\text { Collision detection pada tombol material } \\
\text { lantai } \\
\text { - } \begin{array}{l}\text { Collision detection pada tombol material } \\
\text { furniture }\end{array} \\
\text { - } \\
\text { Collision detection pada tombol } \\
\text { Switch on/off }\end{array}$ & Black box \\
\hline 6. & Menu material dinding & - $\quad$ Merubah material dinding & White box \\
\hline 7. & Menu material lantai & - $\quad$ Merubah material lantai & White box \\
\hline 8. & $\begin{array}{l}\text { Menu material } \\
\text { furniture }\end{array}$ & - Merubah material furniture & White box \\
\hline 9. & Menu switch on/off & $\begin{array}{ll}- & \text { Menghidupkan TV } \\
\text { - } & \text { Mematikan TV }\end{array}$ & White box \\
\hline
\end{tabular}


Kesimpulan pengujian white box dan black box adalah aplikasi dapat menjalankan semua masukan (input) dan di proses dengan benar serta aplikasi dapat mengeksekusi semua blueprint tanpa adanya error sehingga menampilkan event sesuai yang diinginkan.

Usability Testing digunakan untuk mengukur seberapa efektif, efisien dan memuaskannya aplikasi architectural visualization yang telah dikembangkan. Adapun parameter yang digunakan untuk pengukuran usability adalah USE Questionnaire. USE Questionnaire dikembangkan oleh Arnold Lund dan rekan di Ameritech, U.S WEST Advanced Technologies. USE merupakan singkatan dari Usefulness (kegunaan), Satisfction (Kepuasan), dan Ease of use (Kemudahan penggunaan). Pada faktor Ease of use dapat dibagi menjadi 2 faktor, yaitu Ease of Learning (kemudahan belajar) dan Ease of Use (kemudahan penggunaan). Pengujian usability dilakukan dengan penyebaran kuisioner berisi sebanyak 17 pertanyaan yang terbagi dalam 4 faktor sesuai dengan faktor-faktor pada USE questionnaire yaitu usefulness, satisfaction, ease of use, dan ease of learning dengan karakteristik responden dengan status pekerjaan sebagai, Mahasiswa, telah bekerja, dan belum bekerja. Karakteristik responden dipilih sedemikian karena responden yang di test memiliki peluang yang besar untuk membeli rumah hunian sendiri. Pengujian validitas dengan 30 responden dengan tingkat kepercayaan 5\% sehingga $r$ hitung harus lebih besar dari 0.361 . Hasil uji validitas setiap pertanyaan valid memiliki $r$ hitung 0.478-0.799. Hasil uji reliabilitas dapat dilihat dari koefisien Croanbach's Alpha pada Tabel 3.

Tabel 3. Hasil Uji Reliabilitas Kuesioner

\begin{tabular}{|c|c|}
\hline Cronbach's Alpha & N of Items \\
\hline 0.884 & 17 \\
\hline
\end{tabular}

Berdasarkan tingkat reliabilitas Cronbach's Alpha yang dijelaskan pada tabel 3, nilai 0,884 berada pada range $0,80<0,884<1,00$ sehingga hasil dari pengujian yang dilakukan menunjukkan bahwa reliabilitas dari kuesioner berada pada kategori reliabilitas sangat tinggi.

Pengukuran usability dilakukan dengan menghitung persentase jawaban dari seluruh responden yang ada. Pengukuran usability yang dilakukan terdiri dari 4 aspek sesuai dengan hasil penelusuran data dengan menggunakan angket yaitu, Usefulness, Ease of Use, Ease of Learning dan Satisfaction. Hasil pengukuran ke empat aspek usability dapat dilihat pada Tabel 4.

\section{Tabel 4. Hasil Pengukuran Usability}

\begin{tabular}{|l|c|c|c|c|}
\hline No & Aspek Usability & Skor Rersponden & Skor Maksimal & $(\%)$ \\
\hline 1 & Usefulness & 510 & 600 & $85 \%$ \\
\hline 2 & Ease of Use & 480 & 600 & $80 \%$ \\
\hline 3 & Ease of Learning & 203 & 240 & $84,5 \%$ \\
\hline 4 & Satisfaction & 491 & 600 & $81,8 \%$ \\
\hline & Total & $\mathbf{1 6 8 4}$ & $\mathbf{2 0 4 0}$ & $\mathbf{8 2 , 5 \%}$ \\
\hline
\end{tabular}

Nilai persentase kelayakan sebesar $82,5 \%$ berada pada interval 81 sampai $100 \%$ yang menunjukkan bahwa hasil pengukuran usability aplikasi architectural visualization yang dibangun memiliki nilai "sangat layak".

\section{Kesimpulan}

Pembuatan aplikasi interior architectural menggunakan visualization unreal engine4 mampu menghasilkan aplikasi yang layak. Kelayakan tersebut ditunjukkan pada hasil pengujian white box dan black box dimana semua fitur aplikasi dapat berjalan dengan baik, serta pengukuran aspek usability secara keseluruhan menghasilkan nilai persentase kelayakan sebesar 82,5\% yang menunjukkan bahwa hasil pengukuran usability aplikasi memiliki nilai yang "sangat layak" atau dengan kata lain sistem sangat berguna dalam hal menampilkan visualisasi dari desain interior sebuah rumah. 


\section{Referensi}

[1] M. Irsyad, "Aplikasi Visualisasi Bangunan Menggunakan Teknologi Augmented Reality," 2019.

[2] E. Chen, K., \& Lee, "A two-point map-based interface for architectural walkthrough," in 2019 IEEE International Symposium on Mixed and Augmented Reality Adjunct (ISMAR-Adjunct), pp. $136-137$.

[3] M. I. Ghazali, F. Samopa, and N. A. Sani, "Pengembangan Peta Interaktif Tiga Dimensi Gedung Rektorat Institut Teknologi Sepuluh Nopember Menggunakan Unity 3D Engine," $J$. Tek. ITS, vol. 1, no. 1, pp. A113-A118, 2015, [Online]. Available: http://ejurnal.its.ac.id/index.php/teknik/article/view/8357.

[4] P. Kaleja and M. Kozlovská, "Virtual Reality as Innovative Approach to the Interior Designing," Sel. Sci. Pap. - J. Civ. Eng., vol. 12, no. 1, pp. 109-116, 2017, doi: 10.1515/sspjce-2017-0011.

[5] T. S. M. Tengku Wook et al., "Campus Virtual Tour Design to Enhance Visitor Experience and Interaction in a Natural Environment," Int. J. Multimed. Its Appl., vol. 10, no. 1/2/3, pp. 77-92, 2018, doi: 10.5121/ijma.2018.10307.

[6] R. R. Camprubi, "Design and Implementation of an Action-Rpg in Unreal Engine 4," p. 71, 2016.

[7] A. Palit, V. Tulenan, and X. B. N. Najoan, "Rancang Bangun Aplikasi Game Adventure Pengenalan Monumen Benteng Moraya," J. Tek. Inform., vol. 14, no. 4, pp. 483-492, 2019, doi: $10.35793 /$ jti.14.4.2019.27657.

[8] M. Muzammul, M. Awais, M. Umer ghani, M. I. Manzoor, M. Kashif, and M. Y. Saeed, "Applied artificial intelligence in 3D-game (HYSTERIA) using UNREAL ENGINE4," Int. J. Adv. Comput. Sci. Appl., vol. 9, no. 9, pp. 319-325, 2018, doi: 10.14569/ijacsa.2018.090942.

[9] R. L. Afif, K. I. Satoto, and K. T. Martono, "Perancangan PC Game First Person Shooter Menggunakan Unreal Development Kit," J. Teknol. dan Sist. Komput., vol. 2, no. 2, pp. 149156, 2014, doi: 10.14710/jtsiskom.2.2.2014.149-156.

[10] E. Christopoulou and S. Xinogalos, "Overview and Comparative Analysis of Game Engines for Desktop and Mobile Devices," Int. J. Serious Games, vol. 4, no. 4, pp. 21-36, 2017, doi: 10.17083/ijsg.v4i4.194.

[11] J. F. Peter L. Newton, Unreal Engine 4 AI Programming Essentials. Packt Publishing Ltd.

[12] D. Michalík, M. Jirgl, J. Arm, and P. Fiedler, "Developing an unreal engine 4-based vehicle driving simulator applicable in driver behavior analysis - a technical perspective," Safety, vol. 7, no. 2, 2021, doi: 10.3390/safety7020025.

[13] and N. M. Lee, Joanna, John P. Doran, Unreal Engine: Game Development from A to Z. Packt Publishing Ltd., 2016.

[14] M. Armanda, A. F., \& Rizqi, "Game 3d Perjuangan Rakyat Surabaya Dalam Pertempuran 10 November 1945 Dengan Belanda Menggunakan Unreal Engine," ournal Animat. Games Stud., vol. 6, no. 2, pp. 87-96, 2020.

[15] “Unreal Engine.” https://www.unrealengine.com/en-US/. 